\title{
The Rho3 and Rho4 small GTPases interact functionally with Wsc1p, a cell surface sensor of the protein kinase $\mathrm{C}$ cell-integrity pathway in Saccharomyces cerevisiae
}

\author{
Helder Fernandes, $\uparrow$ Olivier Roumanie, $†$ Sandra Claret,ł Xavier Gatti, \\ Didier Thoraval, François Doignon and Marc Crouzet
}

Correspondence

François Doignon

doignon@u-bordeaux2.fr

Received 26 May 2005

Revised 11 November 2005

Accepted 23 November 2005

\begin{abstract}
Laboratoire de Biologie Moléculaire et de Séquençage, Institut de Biochimie et Génétique Cellulaires, UMR Université Victor Segalen Bordeaux 2-CNRS 5095, box 64, 146 rue Léo Saignat, 33076 Bordeaux Cedex, France
\end{abstract}

\begin{abstract}
Rgd1, a GTPase-activating protein, is the only known negative regulator of the Rho3 and Rho4 small GTPases in the yeast Saccharomyces cerevisiae. Rho3p and Rho4p are involved in regulating cell polarity by controlling polarized exocytosis. Co-inactivation of RGD1 and WSC1, which is a cell wall sensor-encoding gene, is lethal. Another plasma membrane sensor, Mid2p, is known to rescue the $\operatorname{rgd} 1 \Delta w s c 1 \Delta$ synthetic lethality. It has been proposed that Wsc1p and Mid2p act upstream of the protein kinase $C$ (PKC) pathway to function as mechanosensors of cell wall stress. Analysis of the synthetic lethal phenomenon revealed that production of activated Rho3p and Rho4p leads to lethality in wsc $1 \Delta$ cells. Inactivation of $\mathrm{RHO} 3$ or $\mathrm{RHO} 4$ was able to rescue the $\operatorname{rgd} 1 \Delta w s c 1 \Delta$ synthetic lethality, supporting the idea that the accumulation of GTP-bound Rho proteins, following loss of Rgd1p, is detrimental if the Wsc1 sensor is absent. In contrast, the genetic interaction between RGD1 and MID2 was not due to an accumulation of GTP-bound Rho proteins. It was proposed that simultaneous inactivation of RGD1 and WSC1 constitutively activates the PKC-mitogen-activated protein kinase (MAP kinase) pathway. Moreover, it was shown that the activity of this pathway was not involved in the synthetic lethal interaction, which suggests the existence of another mechanism. Consistent with this idea, it was found that perturbations in Rho3-mediated polarized exocytosis specifically impair the abundance and processing of Wsc1 and Mid2 proteins. Hence, it is proposed that Wsc1p participates in the regulation of a Rho3/4-dependent cellular mechanism, and that this is distinct from the role of Wsc1p in the PKC-MAP kinase pathway.
\end{abstract}

\section{INTRODUCTION}

Monomeric GTPases of the Ras superfamily are key regulators of numerous physiological processes. They are classified into five families: Ras, Rho/Rac/Cdc42, Rab, Sar1/Arf and

†These authors contributed equally to this work.

‡Present address: Laboratoire de Génétique du Développement et Evolution, Institut Jacques Monod, 75251 Paris Cedex 05, France.

Abbreviations: ASR, arrest of secretion response; 5-FOA, 5-fluoroorotic acid; GAP, GTPase-activating protein; HA, haemagglutinin; MAP kinase, mitogen-activated protein kinase; PKC, protein kinase C; WT, wild type.

Supplementary Fig. S1, available with the online version of this paper, shows the detection of phosphorylated and total SIt2p in isogenic WT and rho3-V51 strains grown in synthetic medium, the detection of phosphorylated and total SIt2p in a WT strain co-producing WT, GDPblocked or GTP-blocked forms of Rho3 and Rho4 proteins from pCM185 and pCM189 plasmids, and the detection of phosphorylated and total SIt2 $p$ in a WT strain producing the GTP-blocked form of Rho3p or Rho4p from the pCM185 plasmid.
Ran (Van Aelst \& D'Souza-Schorey, 1997; Etienne-Manneville $\&$ Hall, 2002). In the yeast Saccharomyces cerevisiae, six functional Rho proteins, namely Cdc42 and Rho1-Rho5, have been described (Garcia-Ranea \& Valencia, 1998; Roumanie et al., 2001; Schmitz et al., 2002). Like most members of the Ras superfamily, Rho GTPases cycle between an active GTPbound form and an inactive GDP-bound form to control cell polarity by regulating secretion, actin cytoskeleton organization, and cell wall modelling (Johnson \& Pringle, 1990; Matsui \& Toh-e, 1992a; Robinson et al., 1999; Adamo et al., 2001; Roumanie et al., 2005). The balance between GDP- and GTP-bound forms is regulated by guanine nucleotide exchange factors, which promote GDP release and binding of GTP, and by GTPase-activating proteins (GAPs), which accelerate GTP hydrolysis by Rho proteins (Van Aelst and D'Souza-Schorey, 1997).

The yeast Rgd1 protein is known to possess GAP activity towards both Rho3 and Rho4 small G proteins (Doignon 
et al., 1999). By activating GTP hydrolysis, Rgdlp negatively regulates Rho3/4 GTPases, and lack of Rgd1p leads to an accumulation of the GTP-bound forms of these two small G proteins in the cell (Roumanie et al., 2000). Inactivation of the $R G D 1$ gene is not associated with a defect in cell polarity (de Bettignies et al., 1999); however, it results in an increase in cell mortality in the late-exponential growth phase (Barthe et al., 1998). Rho3p and Rho4p functions are partially redundant, and are involved in cell polarity by regulating polarized exocytosis and actin cytoskeleton organization (Matsui \& Toh-e, 1992b; Roumanie et al., 2005). While no defect is associated with $\mathrm{RHO} 4$ deletion, inactivation of both RHO3 and $\mathrm{RHO} 4$ genes results in a severe growth phenotype, and lysis of cells with small buds. The Rho3 and Rho4 GTPases have been shown to bind the exocyst complex subunit Exo70, and to interact with formins to activate actin cable formation (Robinson et al., 1999; Dong et al., 2003). Moreover, Rho3p has been shown to have a direct role in post-Golgi secretion by enabling polarized fusion of secretory vesicles with the plasma membrane (Adamo et al., 1999). A recent study has demonstrated that regulation of cell polarity by Rho3p is independent of GTP hydrolysis (Roumanie et al., 2005), suggesting that, in yeast, Rgdlp GAP activity functions with other proteins to regulate Rho3p and Rho4p function in cell growth.

Indeed, studies from our laboratory have implicated Rgdlp in the regulation of cell polarity. We have reported the existence of functional interactions between Rgdlp and the Arp2/3 complex activators Vrp1p and Las17p (Roumanie et al., 2000). Genetic interactions between RGD1 and WSC1 genes have also been demonstrated previously (de Bettignies et al., 1999). WSC1 encodes a highly $O$-glycosylated integral membrane protein that acts as a parietal stress sensor once anchored to the plasma membrane (Verna et al., 1997). It has been found that although lack of Rgd1p or Wsclp under standard growth conditions does not have any effect on yeast, the combination of both $\operatorname{rgd} 1 \Delta$ and $w s c 1 \Delta$ mutations leads to cell mortality. At the same time, the Mid2p cell wall sensor, which has functions partially overlapping with those of Wsclp (Ketela et al., 1999), was characterized as a suppressor of the $\operatorname{rgd} 1 \Delta w s c 1 \Delta$ synthetic lethality. Nevertheless, co-deletion of RGD1 and MID2 is not lethal under regular growth conditions, but leads to conditional lethality in the late-exponential growth phase (de Bettignies et al., 1999). At the plasma membrane, both the Wscl and Mid2 proteins monitor the integrity of yeast cell wall, and can activate the protein kinase C (PKC) pathway (Gray et al., 1997; Verna et al., 1997; Jacoby et al., 1998; Ketela et al., 1999; Rajavel et al., 1999; Martin et al., 2000). The PKC pathway is activated in response to various external stresses, including high temperature, low osmolarity, cell wall perturbation, and mating (Heinisch et al., 1999). Pkcl kinase activation is dependent on the interaction with stress-activated Rhol GTPase (Nonaka et al., 1995; Kamada et al., 1996). The PKC pathway is composed of a MAP kinase module involving the Bck1, Mkk1/Mkk2 and Slt2 kinases (Gustin et al., 1998). It is known that activated Wsclp regulates both the PKC pathway and 1,3- $\beta$-glucan synthesis, while Mid2p acts mainly on the PKC pathway (Sekiya-Kawasaki et al., 2002).

To gain insight into the cellular mechanism by which Rgd1p interacts with the cell wall sensor Wscl, we investigated the role of Rho3 and Rho4 GTPases in the $\operatorname{rgd} 1 \Delta$ wsc $1 \Delta$ synthetic lethality. In this study, we report that the lethality involves an accumulation of activated Rho proteins, and that this is detrimental to the survival of $w s c 1 \Delta$ cells; however, the synthetic lethality is not linked to a defect in the MAP kinase module of the PKC pathway. Moreover, functional interactions involving RGD1, and WSC1 or MID2, are distinct. Disturbance in the Golgi-to-plasma-membrane secretion leads to a specific defect in cell wall sensor abundance. Our results support the involvement of Wscl in a cellular pathway connected to Rho3p-regulated trafficking.

\section{METHODS}

Yeast strains and genetic procedures. The Saccharomyces cerevisiae strains used in this study, and their genetic backgrounds, are described in Table 1. All the strains, except rho3-V51, are isogenic to the S288C strain. Standard yeast genetic methods and media preparation were performed as described by Sherman et al. (1986). Unless otherwise indicated, yeast strains were grown at $30^{\circ} \mathrm{C}$. Yeast transformation was performed according to Gietz et al. (1995). Dead cells were visualized by Methylene Blue staining, and enumerated by microscopic examination of at least 300 cells (Rose, 1975). The standard deviation on determination of the percentage of lethality was calculated to be $2 \cdot 5 \%$.

Production of Rho3 and Rho4 GTPases. Production of wildtype (WT), GDP- and GTP-blocked Rho3 and Rho4 proteins was carried out using the pCM plasmid-based system, as described previously (Roumanie et al., 2000). GDP-blocked mutant forms were obtained by substitution of threonine with asparagine at position 30 in Rho3p, and at position 86 in Rho4p. GTP-blocked mutants were obtained by replacing glutamines 74 and 131 with leucine in Rho3 and Rho4, respectively. Repression of protein production from the $\mathrm{pCM}$ system was obtained by adding $1 \mu \mathrm{g}$ doxycycline $\mathrm{ml}^{-1}$ to the medium. Turn-on was induced by putting cells in doxycycline-free medium. Complete activation of production was obtained after about 8 h growth (Gari et al., 1997; Roumanie et al., 2000).

Heat-shock experiments. The heat-shock experiments were performed essentially as described by Martin et al. (2000). In brief, cells were grown overnight at $21{ }^{\circ} \mathrm{C}$ to mid-exponential phase $\left(\mathrm{OD}_{600}\right.$ $0 \cdot 5$ ), and then either shifted to $39^{\circ} \mathrm{C}$, or kept at $21^{\circ} \mathrm{C}$. After $2 \mathrm{~h}$ incubation, proteins were extracted, subjected to SDS-PAGE, transferred to nitrocellulose, and probed with $\alpha$-phospho-Slt $2 p$ antibodies to monitor PKC pathway activation.

Immunoblot analysis. Protein extraction from yeast for Western blot analysis was performed according to Riezman et al. (1983). The YEp352-MID2 ${ }^{3 \mathrm{HA}}$ and YEp352-WSC1 ${ }^{3 \mathrm{HA}}$ plasmids were used to produce Mid2 and $\mathrm{Wsc} 1$ proteins tagged at their C-terminals with a three-repeat haemagglutinin (HA), as described by Rajavel et al. (1999). Blots were probed for phosphorylated Slt2p with $\alpha$-phosphop44/42 MAP kinase (Thr202/Tyr204) antibody from Cell Signalling at $1: 666$ dilution. Total Slt $2 \mathrm{p}$ was detected with $\alpha$-GST-Slt2p antibodies, kindly provided by $\mathrm{H}$. Martin and M. Molina (Universidad Complutense de Madrid, Madrid, Spain), at 1:2500 dilution. Fur4 and Ure2 proteins were detected using specific polyclonal antibodies at $1: 1000$ and $1: 3000$ dilutions, respectively (Silve et al., 1991; Fernandez-Bellot et al., 2002). Anti-HA 12CA5 monoclonal antibody 
Table 1. S. cerevisiae strains used in this study

\begin{tabular}{|c|c|c|}
\hline Strain & Relevant genotype & Source or reference \\
\hline BY806 & 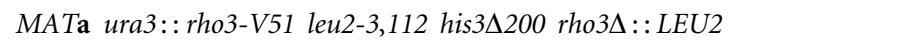 & P. Brennwald \\
\hline LBOR92 & MATa $\operatorname{ura} 3-52$ leu $2 \Delta 1 \operatorname{trp} 1 \Delta 63$ & Our laboratory \\
\hline$b c k 1 \Delta$ & 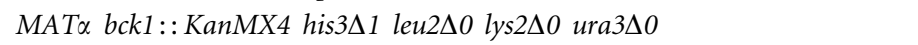 & EUROSCARF* \\
\hline rho4s & MATa ura3-52 rho4::KanMX4 & Our laboratory \\
\hline $\operatorname{rgd} 1 \Delta$ & 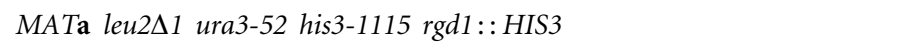 & Our laboratory \\
\hline slt $2 \Delta$ & MATa slt2:: KanMX4 his $3 \Delta 1$ leu2 $\Delta 0$ lys $2 \Delta 0$ ura $3 \Delta 0$ & EUROSCARF \\
\hline$w s c 1 \Delta$ & MATa wsc1:: KanMX4 his $3 \Delta 1$ leu $2 \Delta 0$ lys $2 \Delta 0$ ura $3 \Delta 0$ & EUROSCARF \\
\hline$w s c 1 \Delta$ & 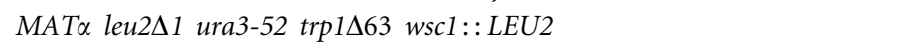 & Our laboratory \\
\hline
\end{tabular}

${ }^{\star}$ European S. cerevisiae Archive for Functional Analysis, Institute for Microbiology, Frankfurt, Germany.

was used at 1:10000 dilution. Primary antibodies were detected with $\alpha$-mouse or $\alpha$-rabbit antibodies coupled to horseradish peroxidase (Pierce) at $1: 10000$ dilution. Protein-antibody complexes were visualized with the Lumi-Light ${ }^{\text {PLUS }}$ system (Roche). Quantification of bands was done using the ImageJ program (National Institutes of Health).

\section{RESULTS}

\section{Accumulation of activated Rho3p in WT cells leads to the $\operatorname{rgd} 1 \Delta$-like phenotype}

In a previous study, we reported that about $20 \%$ of $r g d 1 \Delta$ cells die at the end of the exponential growth phase, when grown in minimal medium (Barthe et al., 1998; de Bettignies et al., 1999). As the GAP domain of Rgd1p negatively regulates Rho3p and Rho4p GTPase activities (Doignon et al., 1999), we decided to explore the involvement of these two small $\mathrm{G}$ proteins in the $\operatorname{rgd} 1 \Delta$ phenotype. We hypothesized that, as a consequence of RGD1 inactivation, there was an accumulation of activated forms of Rho3p and Rho4p, and that this was detrimental to the survival of the yeast. Constitutively activated (GTP-blocked), inactivated (GDPblocked) and WT forms of Rho3p and Rho4p were produced in the WT strain grown in YNB minimal medium, in order to examine the effects on cell morphology and lethality. We observed that the constitutively active Rho3 led to a cell growth defect, as compared with cells containing endogenous Rho3p (control vector) only. Expression of the other mutant forms did not show any detectable growth defect (data not shown). Moreover, microscopic examination of cells producing activated Rho3p or Rho4p revealed heterogeneous morphological defects (Fig. 1A). The morphological alterations were found to increase proportionally with an increase in cell-culture density. For example, at an $\mathrm{OD}_{600}$ of $1 \cdot 5$, half of the yeast cells producing GTP-blocked Rho3p demonstrated abnormally elongated cells, with $10 \%$ of the cells also exhibiting an elongated bud. These observations suggest that cells overproducing activated Rho3p have defects in polarized growth, in agreement with that reported for the constitutively active $r h o 3^{\text {Ala-131 }}$ allele; indeed, rho $3^{\text {Ala-131 }}$ cells have been shown to become elongated and bent (Imai et al., 1996). Upon production of GTPblocked Rho4p, we observed that about $30 \%$ of cells were larger and rounder, with an undefined bud neck. These results indicate impairment of the cytokinesis process.

Regarding the propensity of cells to die upon production of activated Rho proteins, we noted that the percentage lethality was relatively constant and low in the exponential growth phase, but slightly increased in the stationary phase. Importantly, production of GTP-blocked Rho3p led to an increase in cell mortality in the late-exponential phase. The same phenomenon has been observed for the $\operatorname{rgd} 1 \Delta$ mutant grown in minimal medium, at the same stage of cell culture (Barthe et al., 1998). Under our experimental conditions, accumulation of activated Rho3p led to a reproducible $10 \%$ increase in cell mortality when grown in YNB medium, in comparison with an increase of approximately $20 \%$ in cells inactivated for RGD1 (data not shown). We have previously reported that the $\operatorname{rgd} 1 \Delta$ cell lethality is enhanced by increasing the inositol concentration in minimal medium (de Bettignies et al., 2001). Here, we observed that, in YNB medium containing $3 \times$ excess inositol, cell lethality was increased to $16 \%$ upon production of GTP-blocked Rho3p (Fig. 1B). These results suggest that inositol is detrimental to cell survival when Rho3p activation is unbalanced in the cell. Cell mortality observed upon simultaneous production of 
(A)

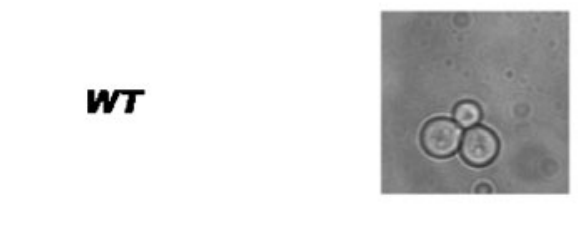

\section{WT
+ Rho3-GTP}
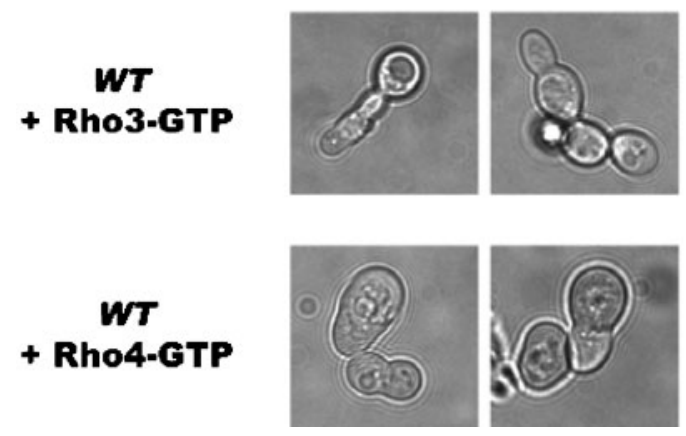

(B)

YNB medium

$+3 x$ inositol

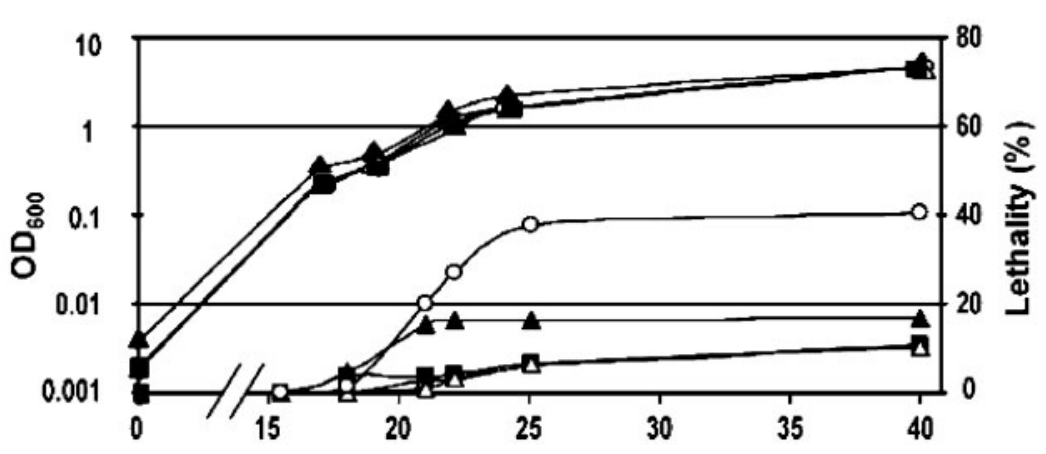

Time (h)

Fig. 1. Morphological defects and lethality associated with production of activated Rho3 and Rho4 GTPases. (A) Micrographs of the representative morphology of WT yeast cells producing constitutively activated forms of Rho3p (Rho3GTP) and Rho4p (Rho4-GTP) from the pCM189 plasmid. An empty plasmid was used as a control. Cells were grown to $\mathrm{OD}_{600} 1.5$ in minimal medium without doxycycline to induce production of Rho3 and Rho4 proteins, and photographs were taken using a phase-contrast microscope. (B) Growth and lethality observed for the rgd1 $1 \Delta$ strain, and WT cells producing activated Rho3 and Rho4 GTPases, in minimal medium with $3 \times$ excess inositol. Growth of cells containing empty pCM189 vector $(\triangle)$, pCM189 producing Rho3-GTP $(\boldsymbol{\Delta})$ and Rho4-GTP $(\boldsymbol{\square})$, and $\mathrm{rgd1} 1 \mathrm{\text {cells }}(\bigcirc)$, was monitored by $\mathrm{OD}_{600}$. Dead cells were counted as described in Methods.

activated Rho3 and Rho4 GTPases was found to be similar to that observed in cells producing activated Rho3p only. We also observed that addition of $1 \mathrm{M}$ sorbitol to the medium did not rescue the cell lethality caused by the production of activated Rho3p. We have previously reported that lethality of $\operatorname{rgd} 1 \Delta$ cells cannot be suppressed by the addition of an osmotic stabilizer (de Bettignies et al., 1999). Taken together, these data suggest that the $\operatorname{rgd} 1 \Delta$ lethality in minimal medium is a consequence of an increase in the amount of activated Rho3p.

\section{The Rho3 and Rho4 small GTPases functionally interact with Wsc1p}

We have previously demonstrated the existence of a synthetic lethal interaction between the $\operatorname{rgd} 1 \Delta$ and $w s c 1 \Delta$ mutations (de Bettignies et al., 1999). In the present study, we investigated the involvement of Rho3 and Rho4 GTPases in $\operatorname{rgd} 1 \Delta w s c 1 \Delta$ lethality. The different forms of Rho3p and Rho4p were independently or simultaneously produced in the $w s c 1 \Delta$ strain, or in the WT strain as a control, to examine the change in cell mortality as a function of growth. Based on the results presented above, and data published previously (de Bettignies et al., 1999), cells were grown in a synthetic complete medium, and not in minimal medium, to prevent an increase in cell mortality due to Rho3p accumulation in the late-exponential phase. Production of the different forms of Rho3p or Rho4p in WT cells had no detectable effect on growth (data not shown). The percentage of cell mortality was found to be low and virtually identical for all WT strains producing the different proteins (Fig. 2A, B). An increase in mortality was observed in late-stationary phase upon co-production of Rho3p and Rho4p (Fig. 2C); we also observed the aforementioned morphological defects that were associated with production of GTP-blocked Rho3p and Rho4p. In contrast to the WT, differences in cell lethality were observed in the $w s c 1 \Delta$ cells producing the different forms of Rho proteins. We observed that the $w s c 1 \Delta$ cells containing the control vector had an intrinsic lethality of about $10 \%$, as reported previously (de Bettignies et al., 1999). In addition to this, production of all the Rho3p forms resulted in an increase in cell lethality (Fig. 2D). After $40 \mathrm{~h}$ induction, production of the WT and GDP-blocked forms of Rho3p led to similar responses, with around $40 \%$ cell mortality. A pronounced effect, nearly $60 \%$ mortality, was observed upon production of activated Rho3p. These data suggest a predominant role for GTP-bound Rho3p in the synthetic lethality observed in the $\operatorname{rgd} 1 \Delta w s c 1 \Delta$ strain. The results obtained using the different forms of Rho4p strongly suggest that it also plays an important role in $\operatorname{rgd} 1 \Delta w s c 1 \Delta$ lethality (Fig. 2E). However, unlike the results obtained with Rho3p, production of GTP- and GDPblocked forms of Rho4p led to similar increases in cell mortality. In order to understand why the production of GTP- and GDP-blocked Rho4p led to the production of 
(A)

WT

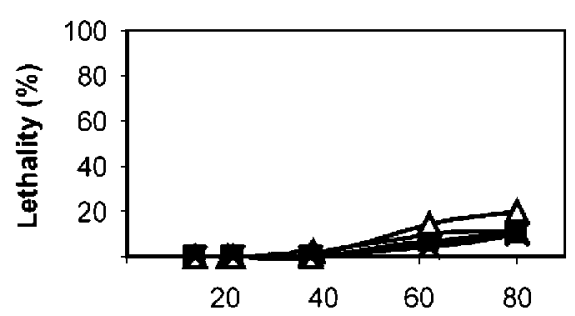

(B)

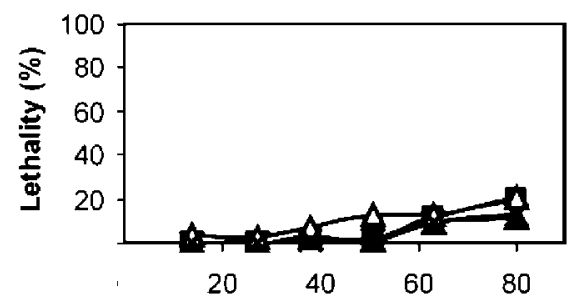

(C)

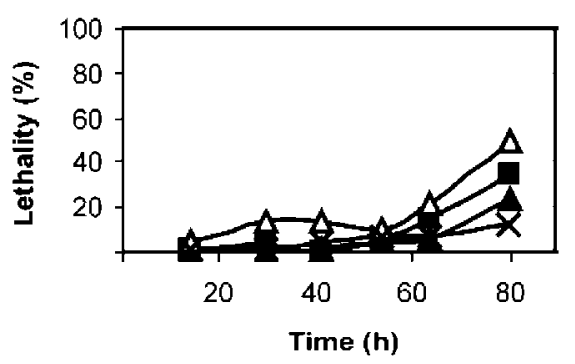

(D) wsc1 1

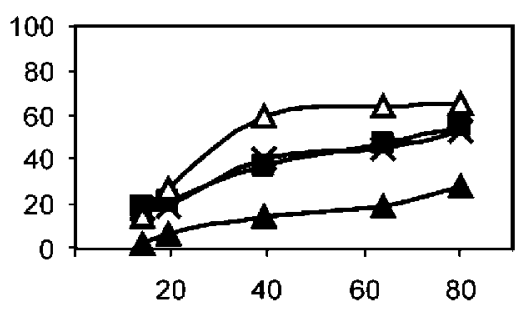

(E)

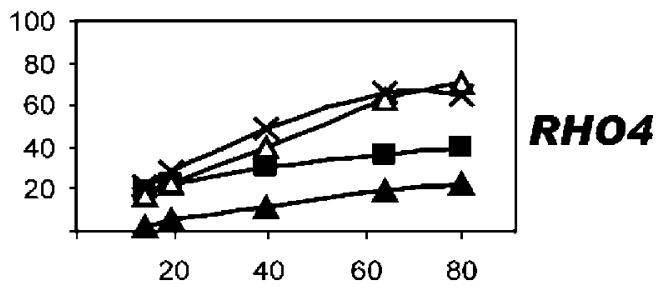

(F)

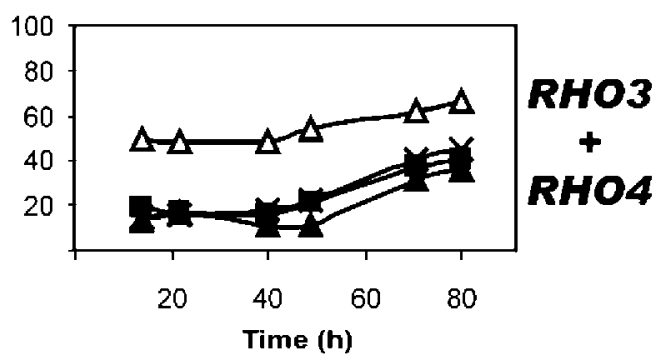

(G)

wsc1 1 rho4 $\Delta$

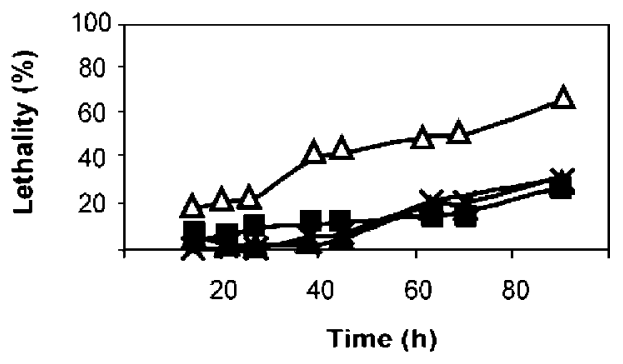

RHO4

Fig. 2. Cell lethality results obtained from cultures of WT and wsc1 $1 \Delta$ strains producing different forms of Rho3 and Rho4 GTPases. (A, B) WT cells containing empty pCM189 plasmid ( $\boldsymbol{\Delta}$ ), and WT cells producing WT Rho3p or Rho4p ( $\boldsymbol{\square})$, GDPblocked Rho3p or Rho4p $(\times)$, and GTP-blocked Rho3p or Rho4p $(\triangle)$, from the pCM189 plasmid, were grown in synthetic medium without doxycycline to induce Rho production at $t=0$. Cell lethality was determined during growth, as described in Methods. (C) Lethality of WT cells co-producing WT ( $\boldsymbol{\square})$, GDP-blocked $(\times)$ and GTP-blocked $(\triangle)$ forms of Rho3 and Rho4 proteins from $p C M 185$ and pCM189 plasmids. An empty vector was used as a control $(\mathbf{\Delta})$. (D, E, F) Experiments similar to those shown in $(\mathrm{A}, \mathrm{B}, \mathrm{C})$ were performed in the wsc1 $1 \Delta$ genetic background. (G) Lethality of wsc $1 \Delta$ rho $4 \Delta$ cells producing WT, inactivated and activated forms of Rho4p; the symbols are the same as for (E).

similar phenotypes, we analysed the effect of different forms of the GTPase in the wsc $1 \Delta$ strain inactivated for $\mathrm{RHO} 4$, thus eliminating the possibility that the concomitant synthesis of WT Rho4 protein from the chromosomal $\mathrm{RHO} 4$ gene was affecting cell lethality. Thus, we followed the mortality of the $w s c 1 \Delta$ rho $4 \Delta$ cells producing WT, GDP- and GTP-blocked Rho4p from the plasmid (Fig. 2G). We observed that in this genetic background, the production of GTP-blocked Rho4p 
significantly increased cell mortality, which was approximately $50 \%$ after $40 \mathrm{~h}$. Contrary to that observed in the $w s c 1 \Delta$ background, production of WT or GDP-blocked Rho4p in $w s c 1 \Delta r h o 4 \Delta$ cells did not lead to an increase in cell mortality, with regard to the control vector. Thus, simultaneous synthesis of activated Rho4p from the chromosomal RHO4, and mutant forms from the plasmid, has a notable effect on the growth of the wsc1s cells.

We further analysed the effect of the co-production of activated, inactivated and WT forms of Rho3p and Rho4p in $w s c 1 \Delta$ cells (Fig. 2F). Co-production of the GTP-active forms led to a significant increase in cell mortality, nearly $50 \%$ after $40 \mathrm{~h}$, which was almost completely rescued by addition of $1 \mathrm{M}$ sorbitol to the medium (data not shown). Importantly, the synthetic lethality between the $w s c 1 \Delta$ and rgd1 $1 \Delta$ mutations is also known to be suppressed by the addition of an osmotic stabilizer (de Bettignies et al., 1999). The lethality observed with the wscl $1 \Delta$ cells containing control vectors, or co-producing the WT or GDP-blocked forms of Rho3p and Rho4p, was in the order of $20 \%$ after 40 h. Thus, Rho3p and Rho4p in their GTP-bound forms have strong cumulative negative effects on the survival of $w s c 1 \Delta$ cells. These results strongly suggest that the accumulation of activated Rho3p and Rho4p following inactivation of RGD1 is detrimental to the survival of cells lacking the WSC1 gene. Notably, it has been shown previously that the synthetic lethality between the $r g d 1$ and $\operatorname{vrp} 1$ mutations is a consequence of an accumulation of GTP-bound Rho3 and Rho4 GTPases (Roumanie et al., 2000).

\section{Inactivation of the $\mathrm{RHO3}$ or $\mathrm{RHO4}$ gene suppresses the rgd1 $\Delta$ wsc1 $1 \Delta$ synthetic lethality}

We next investigated whether the $\operatorname{rgd} 1 \Delta w s c 1 \Delta$ synthetic lethality could be rescued by inactivating the $\mathrm{RHO} 3$ or RHO4 genes. Since activated Rho3p and Rho4p are detrimental to the $w s c 1 \Delta$ cell survival, we hypothesized that reducing the amount of these GTPases would help to keep the cells alive. Accordingly, to assay for suppression, we crossed strains containing the $w s c 1 \Delta r h o 3 \Delta$ and $r g d 1 \Delta$ mutations or the $\operatorname{rgd} 1 \Delta r h o 4 \Delta$ and $w s c 1 \Delta$ mutations to evaluate the phenotypes of cells containing the three mutations. Crosses involving the $w s c 1 \Delta r h o 3 \Delta$ strain were performed in the presence of $1 \mathrm{M}$ sorbitol to prevent cell lysis (Matsui \& Toh-e, 1992b). In agreement with the working hypothesis, the $r g d 1 \Delta w s c 1 \Delta r h o 3 \Delta$ and $r g d 1 \Delta w s c 1 \Delta$ rho $4 \Delta$ triple mutants were found to be viable (Fig. $3 \mathrm{~A}$ ).

Next, we determined the cell mortality by growing the two triple mutant strains in complete medium. The analysis showed that mortality associated with the $\operatorname{rgd} 1 \Delta w s c 1 \Delta$ mutations was strongly suppressed by inactivation of $\mathrm{RHO} 4$ (Fig. 3B). The rho $4 \Delta$ mutation suppressed more than $85 \%$ of cell lethality in the exponential growth phase. Levels of growth of the WT and $r g d 1 \Delta w s c 1 \Delta r h o 4 \Delta$ strains were found to be similar (data not shown). Inactivation of the RHO3 gene also led to a suppressor effect on $\operatorname{rgd} 1 \Delta w s c 1 \Delta$ cell mortality. The strength of the suppression was not as great as
(A) $\operatorname{rgd1} \Delta$

$\operatorname{rgd1} \Delta \operatorname{wsc} 1 \Delta$

$\operatorname{rgd1} \Delta w s c 1 \Delta r h 04 \Delta$

$\operatorname{rgd1} \Delta w s c 1 \Delta r h o 3 \Delta$

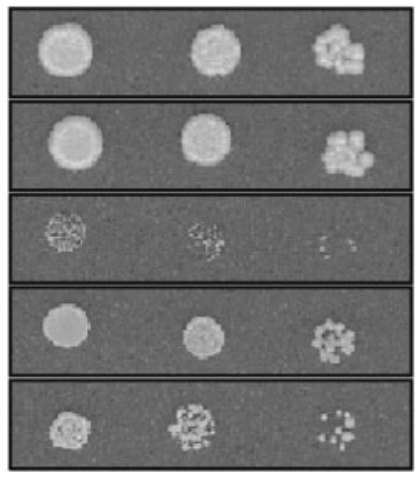

(B)

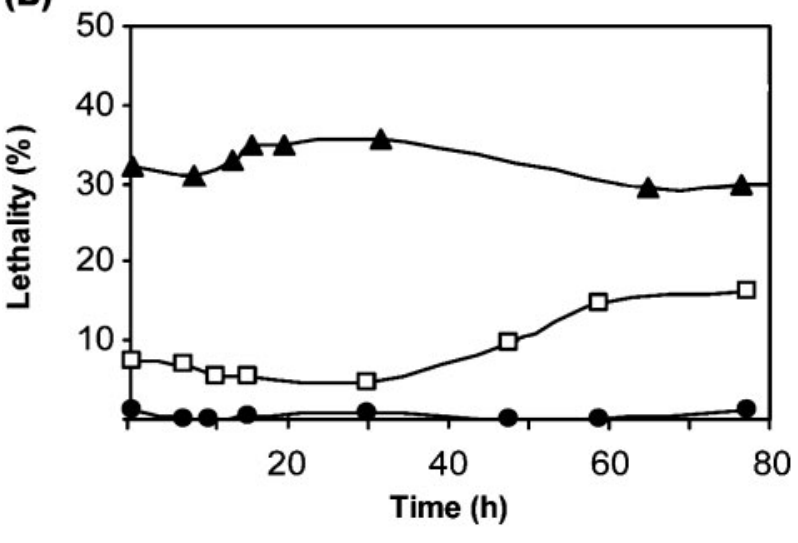

Fig. 3. Inactivation of $\mathrm{RHO} 3$ or $\mathrm{RHO} 4$ suppresses rgd1 $1 \mathrm{wsc} 1 \Delta$ synthetic lethality. (A) Growth of mutant strains was tested by spotting tenfold serial dilutions of cells onto minimal medium, and the plates were incubated for 2.5 days at $30^{\circ} \mathrm{C}$. (B) WT

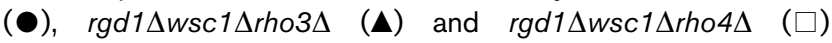
strains were grown in complete medium, and cell lethality was measured during growth, as described in Methods.

that for the rho $4 \Delta$ mutation; about $30 \%$ of the triple mutant $\operatorname{rgd} 1 \Delta w s c 1 \Delta r h o 3 \Delta$ cells still died in the early growth phase (Fig. 3B). However, we observed that addition of $1 \mathrm{M}$ sorbitol to the medium increased rho3 $\Delta$ suppression to the level observed with the rho4 $\Delta$ mutation (data not shown). Taken together, these results show that both rho3 and rho4 mutations rescue the growth and lethality defects associated with the $\operatorname{rgd} 1 \Delta w s c 1 \Delta$ mutations. Hence, reduced levels of activated Rho3 or Rho4 GTPases within the $\operatorname{rgd} 1 \Delta w s c 1 \Delta$ cells suppress the synthetic lethal phenotype, which is consistent with the mechanism suggested by our analysis of interactions between Wsclp and the two GTPases.

\section{The functional interaction between RGD1 and MID2 is not dependent on Rho3 and Rho4 GTPases}

In a previous study, we reported that $R G D 1$ interacts genetically with the cell wall sensor-encoding gene MID2, and it was observed that inactivation of MID2 enhances the $\operatorname{rgd} 1 \Delta$ phenotype, and that the double mutant strain has a higher number of dead cells in late-exponential growth 
phase in minimal medium (de Bettignies et al., 1999). Based on the data presented above, we investigated whether activated Rho3 and Rho4 GTPases were involved in the $r g d 1 \Delta$ mid $2 \Delta$ genetic interaction. We produced the different forms of Rho3p and Rho4p in mid2 $\Delta$ cells, and in WT cells as a control. Cells were grown in YNB minimal medium, and the lethality was monitored at different times. As expected, results obtained with WT control cells were similar to those described above. Production of WT, GDP- and GTPblocked Rho GTPases in the mid2 $\Delta$ cells did not lead to any increase in mortality, with respect to control cells (data not shown). In addition, the lethality of the $\operatorname{rgd} 1 \Delta$ mid $2 \Delta$ mutant was not rescued by $\mathrm{RHO} 3$ or $\mathrm{RHO} 4$ inactivation (data not shown). These results indicate that the Rho3 and Rho4 GTPases are not involved in the interaction between RGD1 and MID2.

\section{The PKC pathway is constitutively active in the rgd $1 \Delta w s c 1 \Delta r h 03 \Delta$ and $r g d 1 \Delta w s c 1 \Delta r h 04 \Delta$ triple mutants}

The Wscl protein is a major sensor for cell wall integrity signalling that acts upstream of Pkclp and the Bck1/ Mkk1,2/Slt2 MAP kinase cascade (Ketela et al., 1999; Philip \& Levin, 2001). We have previously reported that inactivation of $R G D 1$ reduces Rlm1p transcriptional activity, as well as transcription of PST1, which is a target of the PKC pathway; moreover, it has been shown that viability of the $r g d 1 \Delta$ cells in the late-exponential phase is restored by overactivation of the PKC pathway (de Bettignies et al., 2001). Thus, one possibility is that in the $r g d 1 \Delta w s c 1 \Delta$ cells, weakening of the cell wall, and a decrease in the activity of the PKC pathway, might be responsible for the synthetic lethality. Consistent with this hypothesis, and as known for mutants defective in the PKC pathway, growth of the $\operatorname{rgd} 1 \Delta w s c 1 \Delta$ mutant is restored by addition of an osmotic stabilizer to the medium (Cid et al., 1995; de Bettignies et al., 1999). We investigated the activity of the PKC pathway in the $\operatorname{rgd} 1 \Delta w s c 1 \Delta r h o 3 \Delta$ and $\operatorname{rgd} 1 \Delta w s c 1 \Delta r h o 4 \Delta$ triple mutants described above by monitoring phosphorylation of Slt2p. The Slt2 protein is specifically phosphorylated on residues $\mathrm{Thr}^{190}$ and $\mathrm{Tyr}^{192}$ upon activation of the PKC pathway (Lee et al., 1993). As expected, we found that the control WT strain, as well as the $\operatorname{rgd} 1 \Delta$ and $w s c 1 \Delta$ mutants, did not have a detectable amount of activated Slt2p. However, a significantly higher amount of phosphorylated Slt2p was observed in the $\operatorname{rgd} 1 \Delta w s c 1 \Delta r h o 3 \Delta$ and $\operatorname{rgd} 1 \Delta w s c 1 \Delta r h o 4 \Delta$ triple mutants grown in complete medium at a regular temperature $\left(30^{\circ} \mathrm{C}\right)$ (Fig. $\left.4 \mathrm{~A}\right)$. Surprisingly, the abundance of Slt2 protein was increased in the wsc $1 \Delta$ strain only, even though activity of the PKC pathway was not stimulated (Fig. 4A).

It is known that Slt2p phosphorylation is stimulated upon heat shock of yeast cells (Kamada et al., 1995). As inactivation of RHO4 strongly suppresses the $r g d 1 \Delta w s c 1 \Delta$ synthetic lethality in medium without an osmotic stabilizer (Fig. 3), we next determined the Slt2p phosphorylation state in the $\operatorname{rgd} 1 \Delta w s c 1 \Delta r h o 4 \Delta$ triple mutant, and in control strains, following heat shock. Although suppression of the synthetic lethality by inactivation of $\mathrm{RHO} 3$ is not as effective as with

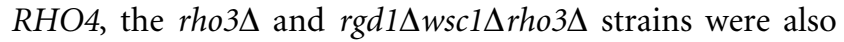
included in the experiment to look for common physiological responses between the two triple mutants. The different strains were grown in minimal medium to mid-exponential phase at $21^{\circ} \mathrm{C}$, and then half of the culture was transferred to $39^{\circ} \mathrm{C}$ for $2 \mathrm{~h}$, while the other half was kept at $21^{\circ} \mathrm{C}$, and Slt2p phosphorylation was monitored at both temperatures (Fig. 4B). As shown above, the two triple mutant strains showed a constitutive activation of Slt2p phosphorylation at the regular temperature; none of the other strains showed a detectable amount of activated Slt $2 \mathrm{p}$ at $21^{\circ} \mathrm{C}$. Temperature shift to $39^{\circ} \mathrm{C}$ resulted in an overall increase in Slt2 phosphorylation for all the strains tested. However, quantification of the amount of activation showed that, although WT and rho4 $\Delta$ cells were able to significantly increase phosphorylation of Slt2p, other strains tested showed a partial decrease in the activation of Slt2p phosphorylation (Fig. 4B). Importantly, the two triple mutants showed almost no increase in phosphorylation upon heat shock. Similar defects were observed when we measured the increase in the abundance of Slt2 protein after heat shock (Fig. 4B). Thus, stressing cells inactivated for RGD1 and WSC1 did not induce an additional increase in Slt2p phosphorylation. Altogether, our results suggest that the PKC pathway is constitutively active following inactivation of both the RGD1 and WSC1 genes. Hence, it seems unlikely that the $\operatorname{rgd} 1 \Delta w s c 1 \Delta$ synthetic lethality could be a consequence of a defect in PKC pathway activity.

\section{The PKC pathway is not involved in the rgd1 $\Delta w s c 1 \Delta$ synthetic lethality}

The aforementioned observations led to the suggestion that the synthetic lethality may not be linked to the PKC pathway. To precisely analyse the involvement of PKC pathway activity in the $\operatorname{rgd} 1 \Delta w s c 1 \Delta$ interaction, we investigated the suppressor effect of genes encoding components of this pathway. We examined whether a single-copy plasmid containing a $B C K 1-20$ activated allele, or multicopy plasmids containing RHO1 or MKK1 (de Bettignies et al., 2001), could suppress the synthetic lethality. The original synthetic lethal strain SLRGD1-1, which already contains a URA3 centromeric plasmid with the RGD1 gene (de Bettignies et al., 1999), was transformed with the different plasmids. The transformants were tested for growth on control and 5-fluoroorotic acid (5-FOA) plates to examine their ability to lose the URA3/RGD1 plasmid. An empty plasmid, and a high-copy plasmid containing RGD1 (de Bettignies et al., 2001), were used as negative and positive controls, respectively. We observed that overexpression of RHO1, BCK1-20 or $M K K 1$ genes did not rescue the growth defect associated with the synthetic lethality (Fig. 5A). This result indicates that overactivation of the PKC-MAP kinase cascade is not sufficient to suppress cellular defects following inactivation of RGD1 and WSC1 genes.

In order to gain additional evidence, we examined the interaction between the $\operatorname{rgd} 1 \Delta$ mutation, and $B C K 1$ and 


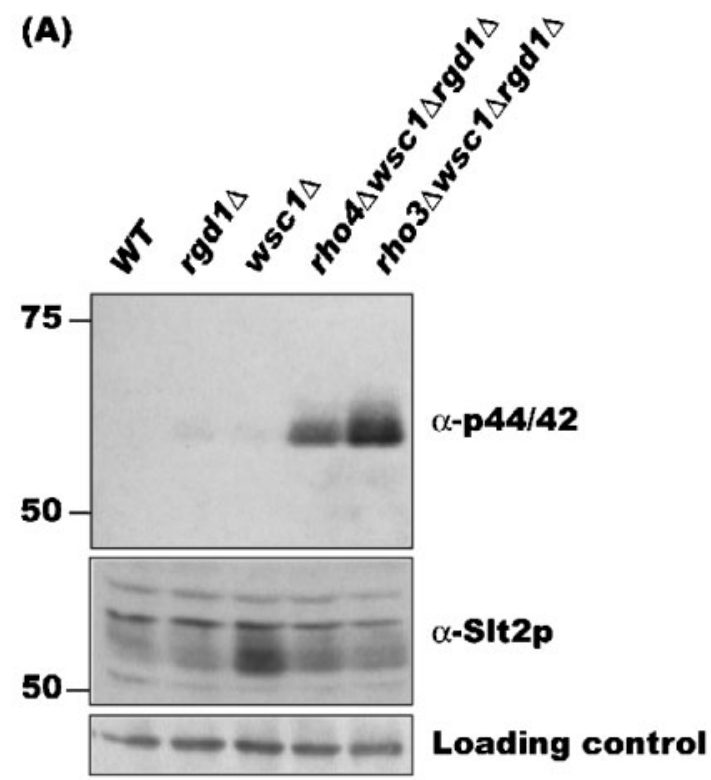

(B)
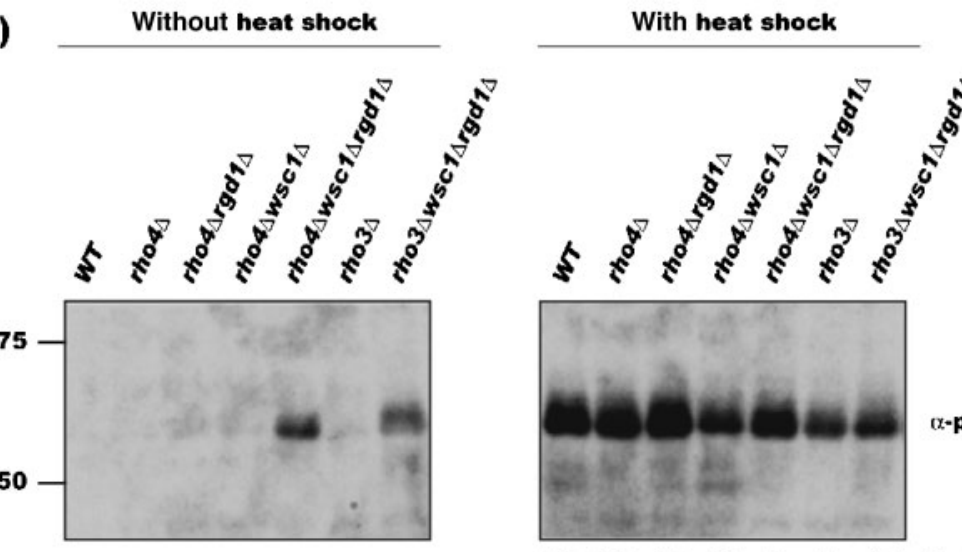

$\begin{array}{llllllll}39 & 33 & 15 & 11 & 2 & 7 & 1.5 & \text { Fold-increase }\end{array}$
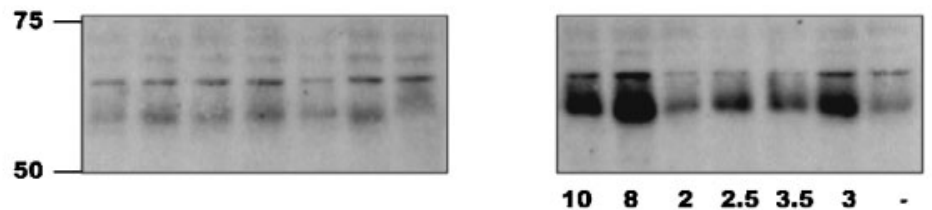

in phospho-sit2p

$\alpha-\mathbf{S I t 2 p}$

Fold-increase in total SIt2p

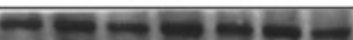

Loading control

Fig. 4. The PKC-MAP kinase pathway is constitutively activated in rho3 $\Delta$ wsc $1 \Delta$ rgd $1 \Delta$ and rho $4 \Delta$ wsc $1 \Delta r g d 1 \Delta$ mutants. (A) Detection of Slt2 MAP kinase phosphorylation in WT, rgd1 1 , wsc1 $1 \Delta$ and two triple-mutant strains grown in complete medium at $30^{\circ} \mathrm{C}$. Slt2 $p$ activation was detected with $\alpha$-p44/42 antibodies. Total Slt2 protein was visualized with polyclonal $\alpha$-Slt2 antibodies. A cross-reacting protein was used as a loading control. Results similar to those in (A) were obtained with cells grown in minimal medium at $30^{\circ} \mathrm{C}$. (B) Detection of Slt2p activation following heat shock in WT and mutant strains. The strains were grown in minimal medium at $21^{\circ} \mathrm{C}$ to mid-exponential phase, and then half of the cells was quickly transferred to $39^{\circ} \mathrm{C}$ for $2 \mathrm{~h}$ (with heat shock), and the other half was kept at $21^{\circ} \mathrm{C}$ (without heat shock). Phosphorylated and total Slt2 proteins were detected as described for (A). The increase in phosphorylated and total Slt2p upon heat shock was quantified by band densitometry. The fold-increase results are presented as ratios 'with heat shock'/'without heat shock'. 

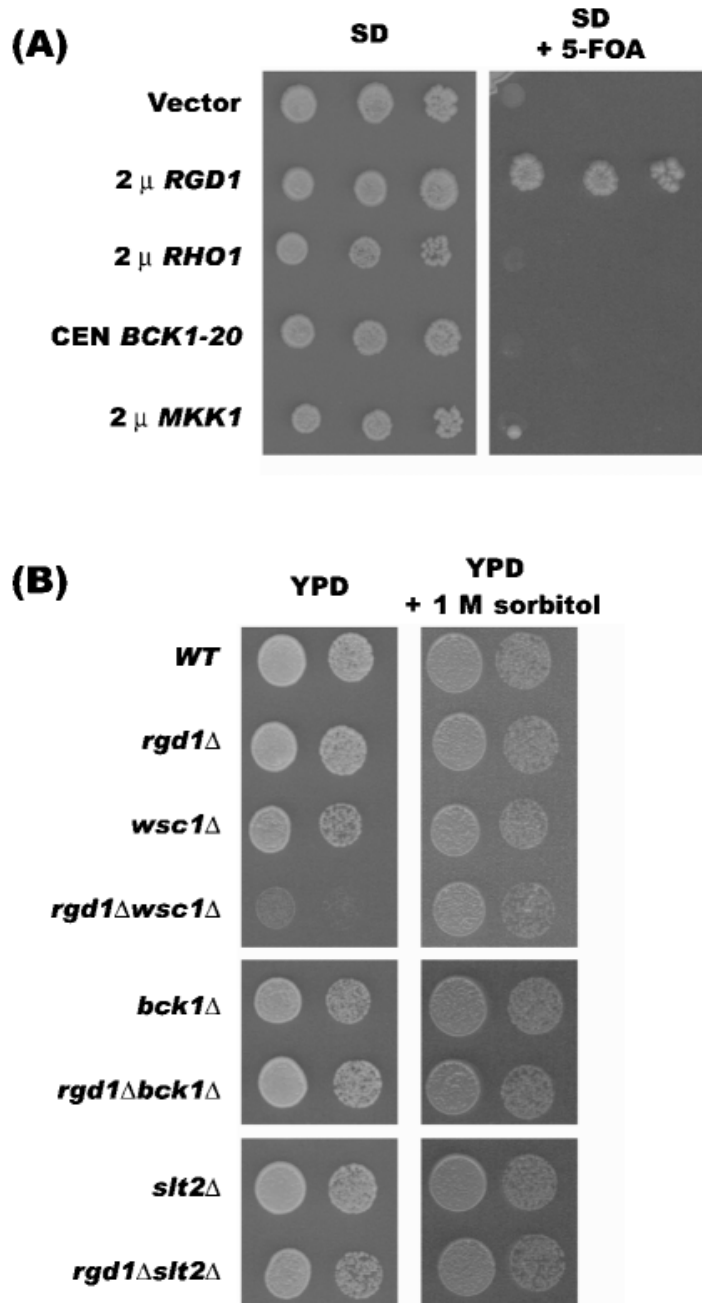

Fig. 5. The PKC-MAP kinase pathway is not involved in the $\operatorname{rgd} 1 \Delta w s c 1 \Delta$ synthetic lethality. (A) Tests of suppression of rgd1 1 wsc1 $1 \Delta$ synthetic lethality by components of the PKC pathway. The $r g d 1 \Delta w s c 1 \Delta$ synthetic lethal strain containing a low-copy (CEN) URA3/RGD1 vector was transformed with an empty control vector, a CENITRP1 vector containing the activated BCK1-20 allele, and a multicopy ( $2 \mu$ ) LEU2 vector containing $R G D 1, R H O 1$ or MKK1. Plasmid-shuffle complementation assays were then performed on control SD and selective 5-FOA plates. (B) Analysis of the growth phenotype of the $\operatorname{rgd} 1 \Delta b c k 1 \Delta$ and rgd $1 \Delta$ slt2 $\Delta$ double mutants. $r g d 1 \Delta$ was crossed to the bck1 strain, and to the slt2 $\Delta$ strain, and tetrads were dissected on complete medium containing $1 \mathrm{M}$ sorbitol. The $\mathrm{rgd1 \Delta}$ and wsc1 $1 \Delta$ mutations were also combined as a control. Growth of control and double-mutant strains was monitored on complete medium, either with or without $1 \mathrm{M}$ sorbitol.

SLT2, which are two genes encoding the first and last kinases of the PKC-MAP kinase module, respectively. To perform this analysis, $r g d 1 \Delta$ was crossed to a $b c k 1 \Delta$ strain, and to a slt $2 \Delta$ strain, the diploid cells were allowed to sporulate, and the tetrads were dissected on complete medium containing $1 \mathrm{M}$ sorbitol. As a control, the $r g d 1 \Delta$ and $w s c 1 \Delta$ strains were also crossed. Growth of double-mutant strains was then analysed on complete medium, either with or without an osmotic stabilizer (Fig. 5B). As expected, the $\operatorname{rgd} 1 \Delta w s c 1 \Delta$ double-mutant strain was non-viable on medium lacking sorbitol. Importantly, we observed that the $r g d 1 \Delta b c k 1 \Delta$ and rgd1 $1 \Delta$ slt $2 \Delta$ double mutants did not exhibit any growth defect on medium lacking sorbitol, indicating the absence of synthetic lethality between $R G D 1$ and $B C K 1$, and between $R G D 1$ and SLT2. Hence, these results are consistent with the idea that a defect in PKC pathway activity is not responsible for the $\operatorname{rgd} 1 \Delta w s c 1 \Delta$ synthetic lethal interaction.

\section{Mutations in RHO3 specifically impair the abundance of Wsc1 and Mid2 proteins}

The above results suggest that a cellular process distinct from cell integrity signalling is perturbed when both Rgdlp and Wsclp are absent. Rgdlp acts as a negative regulator of Rho3 and Rho4, which are GTPases that interact with the exocytic apparatus in yeast. It has been demonstrated that activated Rho3p interacts with the exocyst complex, and is important for regulating exocytosis at sites of polarized growth (Robinson et al., 1999; Roumanie et al., 2005). Wsc1 protein is known to be involved not only in sensing cell wall stress, and in activating the PKC pathway, but also in regulating cellular processes connected to secretion. In particular, it has been reported that WSC1 is a multicopy suppressor of the sly 1 mutant defective for endoplasmic-reticulum-Golgi transport (Kosodo et al., 2001). Moreover, signals from the secretory pathway caused by perturbation in intracellular trafficking have been shown to be transduced by the WSC family of proteins. It has been observed that Wsc proteins need to be in intracellular compartments along the secretory pathway to induce the arrest of secretion response (ASR) through activation of Pkclp (Nanduri \& Tartakoff, 2001). Interestingly, the Bck1/Mkk1,2/Slt2 MAP kinase cascade activated by Pkclp does not seem to be required for the ASR, suggesting the existence of a new branch of Pkclp signalling (Ng, 2001). We decided to explore whether alterations in Rho3-dependent cellular trafficking induced defects in Wsc1 protein abundance. We first made use of the rho3 $\Delta$ mutant, in which regulation of polarized exocytosis by GTP-bound Rho3p is lost, and the actin cytoskeleton is depolarized (Roumanie et al., 2002, 2005). To perform this analysis, WT, $\operatorname{rgd} 1 \Delta$, rho $4 \Delta$ and $r h o 3 \Delta$ strains were transformed with a multicopy plasmid containing HA-tagged Wsclp (Rajavel et al., 1999), and the protein abundance was monitored. Although no defect was observed in the WT, or the $\operatorname{rgdl\Delta }$ and rho4 $\Delta$ strains, the amount of Wsclp was strongly reduced in the rho3 $\Delta$ mutant (Fig. 6A). Examination of the transcription factor Ure2, and the plasma membrane protein Fur4, showed no defect in their abundance in the rho3 $\Delta$ compared with the other strains (Fig. 6A). Subsequently, we looked for the abundance of another cell wall sensor, Mid2p, since WSC1 and MID2 have been shown to functionally interact with each other in yeast (de Bettignies et al., 1999). As shown in Fig. 6B, Mid2p was found to be present and highly $O$-glycosylated in all the strains, except $r h o 3 \Delta$. Once 

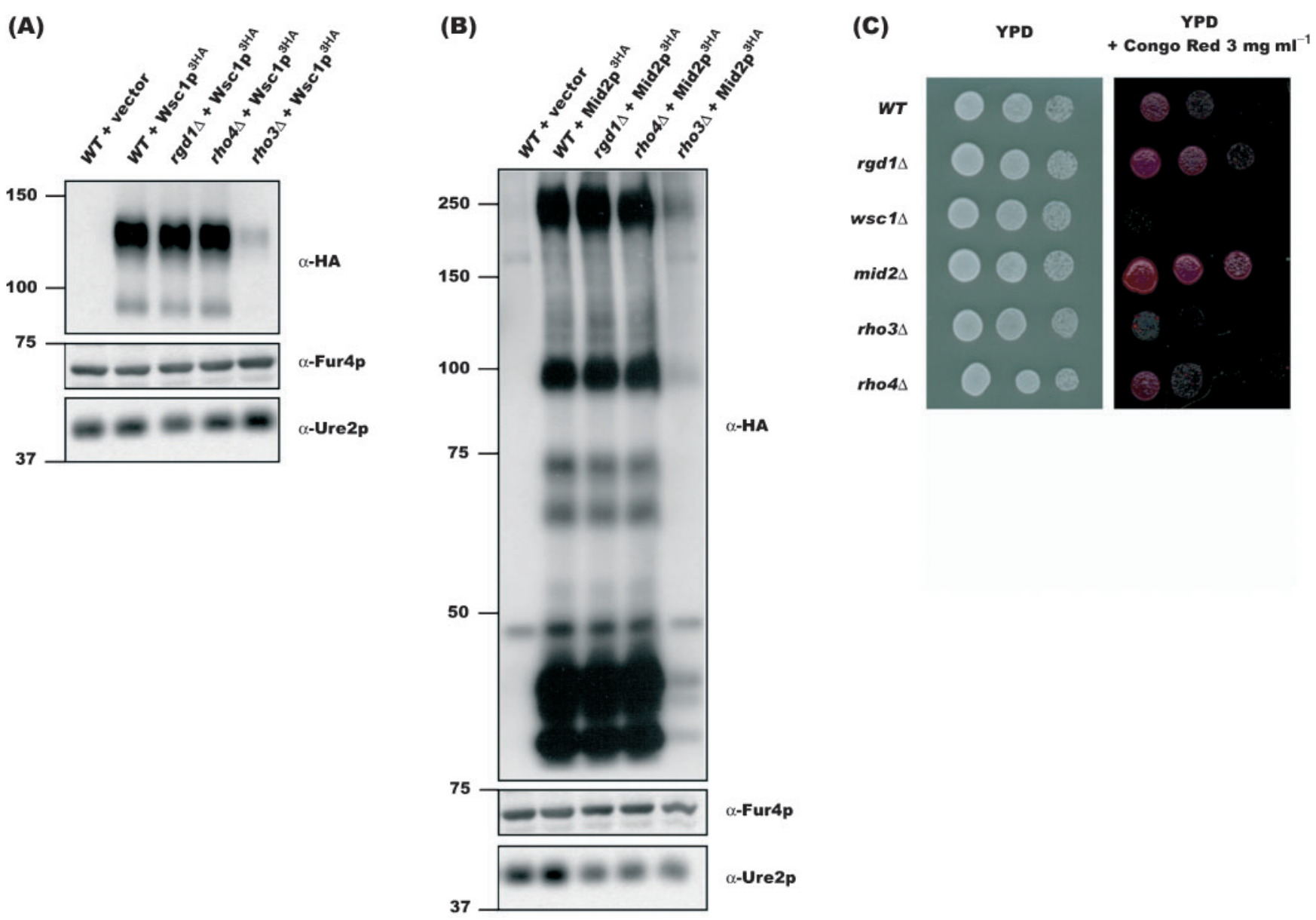

Fig. 6. Abundance of the Wsc1 and Mid2 proteins is strongly reduced in rho3 $\Delta$ cells. (A) Analysis of Wsc1p abundance in WT, $r g d 1 \Delta$, rho4 $\Delta$ and $r h o 3 \Delta$ mutant strains containing the YEp352-WSC1 ${ }^{3 \mathrm{HA}}$ plasmid. An empty vector was used as a control. The strains were grown to early exponential phase in synthetic medium at $30^{\circ} \mathrm{C}$, and total proteins were extracted and subjected to SDS-PAGE, and Wsc1-3HA protein was detected by immunoblot analysis using $12 \mathrm{CA} 5$ antibodies. The control Ure2 and Fur4 proteins were detected using specific polyclonal antibodies. The positions of molecular mass markers $(\mathrm{kDa})$ are indicated on the left. (B) Analysis of Mid2p abundance in $W T, r g d 1 \Delta$, rho4 $\Delta$ and rho3 $\Delta$ mutant strains containing the YEp352-MID2 ${ }^{3 \mathrm{HA}}$ plasmid. Experiments were performed as described for (A). (C) Analysis of the growth phenotype of the rho3 $\Delta$ mutant in the presence of the cell-wall-interfering compound Congo Red. WT and mutant strains were grown in complete medium, and tenfold serial dilutions were spotted onto complete medium (YPD), and YPD containing $3 \mathrm{mg}$ Congo Red $\mathrm{ml}^{-1}$. Plates were incubated for $2-3$ days at $30^{\circ} \mathrm{C}$.

again, no alteration in Ure2p or Fur4p abundance was detected (Fig. 6B). These results point towards a specific defect in the abundance of Wscl and Mid2 proteins in the rho3 $\Delta$ mutant. To investigate stress sensor functionality in the rho3 $\Delta$ mutant, the effect of the cell wall interfering compound Congo Red was tested on growth; we observed that both the wsc $1 \Delta$ and rho3 $\Delta$ strains were unable to grow in the presence of the compound (Fig. $6 \mathrm{C}$ ). As previously reported, the mid $2 \Delta$ mutant and, to a lower extent, the $\operatorname{rgd} 1 \Delta$ mutant were resistant, and grew better than the WT and rho4 $\Delta$ strains on medium containing Congo Red (de Bettignies et al., 1999). These data suggest that the functionality of Wsclp is impaired in rho3 $\Delta$. It has been reported that MID2 is a low-copy suppressor of the $r g d 1 \Delta w s c 1 \Delta$ synthetic lethal interaction, and that the mid $2 \Delta w s c 1 \Delta$ combination is lethal (de Bettignies et al., 1999). Since we observed that the $r g d 1 \Delta$ mutation does not affect Mid2p abundance, our results lend support to the idea that $r g d 1 \Delta w s c 1 \Delta$ co-lethality is not a consequence of a decrease in the abundance of Mid2p following inactivation of RGD1.

Next, we looked at the behaviour of Wsc1 and Mid2 proteins in the rho3-V51 mutant. The cold-sensitive rho3-V51 allele has a specific secretion defect that does not involve, in contrast to the rho3 $\Delta$ mutation, detectable effects on the polarized localization of the exocytic machinery or the actin cytoskeleton (Roumanie et al., 2005). Secretion of the periplasmic enzymes invertase and $\mathrm{Bgl} 2$ has been shown to be perturbed at both permissive $\left(25^{\circ} \mathrm{C}\right)$ and non-permissive $\left(14^{\circ} \mathrm{C}\right)$ temperatures, and the rho3-V51 cells accumulate 
post-Golgi secretion vesicles in the cytosol (Adamo et al., 1999). Thus, we conducted experiments to follow HAtagged Wsclp and Mid2p in rho3-V51 cells and isogenic WT cells at 25 and $14{ }^{\circ} \mathrm{C}$; as shown in Fig. 7(A), we observed a decrease in the abundance of fully $O$-glycosylated Wsclp at both temperatures in the rho3-V51 mutant compared with the WT. Similar results were obtained with Mid2 protein (Fig. 7B); the amount of the fully mature form of Mid2p was reduced, and we observed the appearance of a $150 \mathrm{kDa}$ form of the protein in the rho3-V51 mutant at both 25 and $14{ }^{\circ} \mathrm{C}$ (Fig. 7B). Thus, a specific block in trafficking between the Golgi apparatus and the plasma membrane led to a negative effect on both Wscl and Mid2 proteins. We also examined growth of the rho3-V51 mutant on complete medium containing Congo Red. The rho3-V51 secretion mutant was found to be more sensitive to Congo Red when compared with the WT (Fig. 7C). As the strain background used for studying rho3-V51 has a higher sensitivity to Congo Red than other strains used in this study, we also grew these strains on medium containing $1 \mathrm{M}$ sorbitol as an osmotic stabilizer. Although the addition of sorbitol helped the growth of the WT strain in the presence of Congo Red, rho3V51 did not show a comparable increase under the same conditions (Fig. 7C). Thus, like rho3 sensitive to perturbation of the cell wall, suggesting that cell wall sensors, and in particular Wsclp, are not functional. Finally, these results demonstrate that loss of active Rho3p affects Wsclp and Mid2p behaviour, strongly suggesting that perturbations in polarized exocytosis influence the processing or synthesis of the two proteins. Interestingly,
(A)
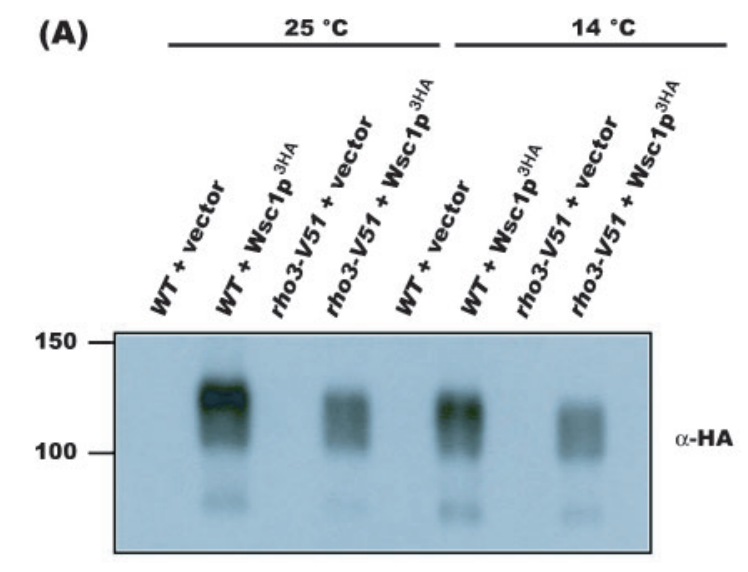

(C)

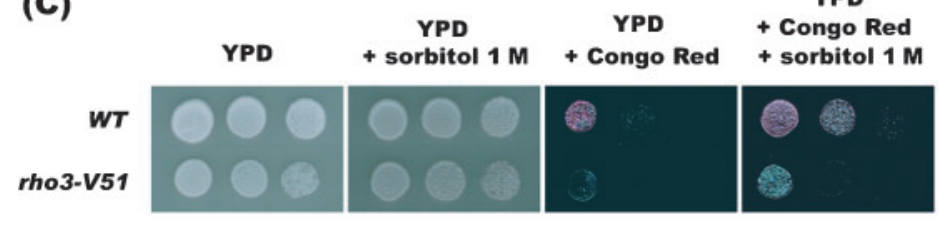

(B)
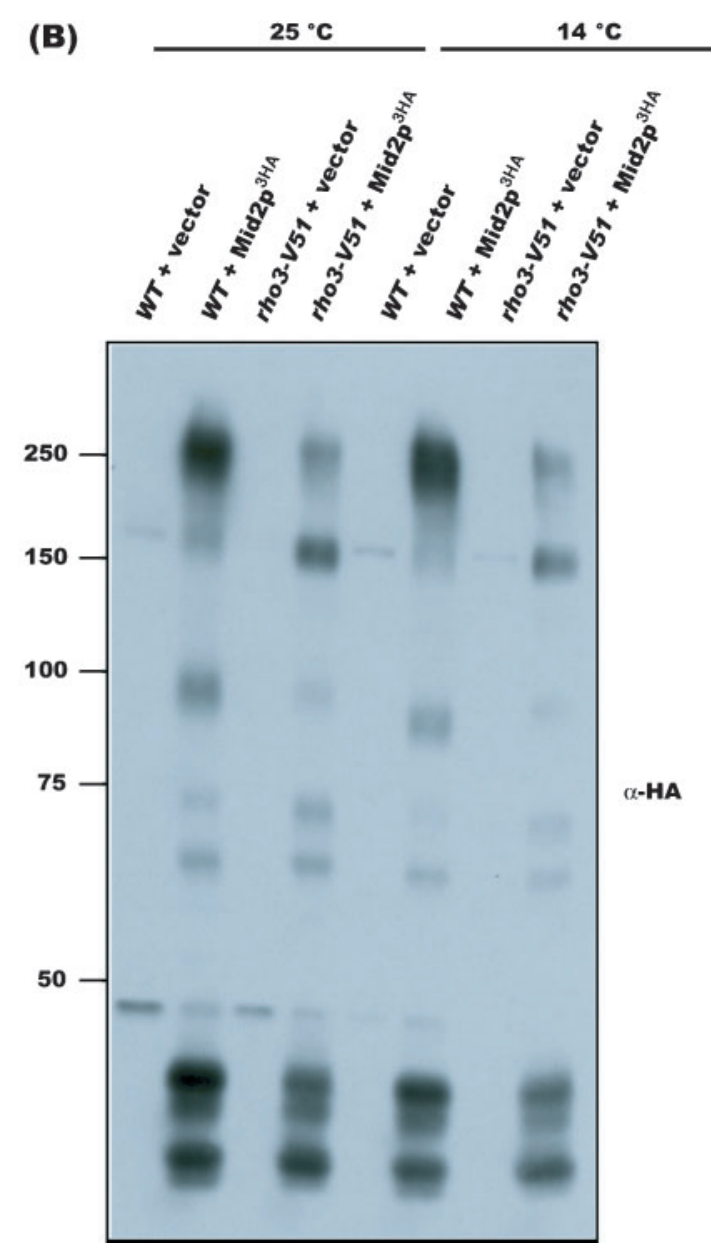

Fig. 7. The Wsc1 and Mid2 proteins are specifically impaired in the rho3-V51 secretion mutant. (A) Analysis of Wsc1p abundance and maturation in isogenic WT and rho3-V51 strains containing the YEp352-WSC1 $1^{3 \mathrm{HA}}$ plasmid, at 25 and $14{ }^{\circ} \mathrm{C}$. Cells were grown to early exponential phase in synthetic medium, and either shifted to $14^{\circ} \mathrm{C}$ for $5 \mathrm{~h}$, or kept at $25^{\circ} \mathrm{C}$. Cells were then processed as described in Fig. 6(A) to detect the Wsc1-3HA protein. An empty vector was used as a control. (B) Analysis of Mid2p abundance and maturation in WT and rho3-V51 strains containing the YEp352-MID2 ${ }^{3 \mathrm{HA}}$ plasmid at 25 and $14{ }^{\circ} \mathrm{C}$. Experiments were performed as described in (A). (C) Analysis of the growth phenotype of the rho3-V51 mutant in the presence of the cell-wall-interfering compound Congo Red. Isogenic WT and mutant strains were grown in complete medium at $25^{\circ} \mathrm{C}$, and tenfold serial dilutions were spotted onto YPD, and YPD containing $3 \mathrm{mg}$ Congo Red $\mathrm{ml}^{-1}$. Strains were also grown on control and selective media containing $1 \mathrm{M}$ sorbitol. Plates were incubated for $2-3$ days at $25^{\circ} \mathrm{C}$. 
similar experiments performed in cells overproducing constitutively active Rho3p showed no alteration in Wscl and Mid2 protein abundance (data not shown). This might imply that only perturbation of polarized exocytosis due to loss of Rho3p, and not overactivation of exocytosis by Rho3p, has a negative effect on Wsc1 and Mid2 proteins in the cell.

\section{DISCUSSION}

We have previously reported the existence of synthetic lethality between the RGD1 and WSC1 genes in the yeast S. cerevisiae. Rgd1 protein is a GAP factor that negatively regulates Rho3p and Rho4p, which are two small GTPases dedicated to the maintenance of cell polarity. Wsclp and Mid2p are the two major cell surface sensors that activate the PKC1-MPK1 cell integrity pathway under stress conditions. If one of the two cell surface proteins is absent, the other becomes essential in the response to stress (de Bettignies et al., 1999; Ketela et al., 1999; Rajavel et al., 1999). MID2 overexpression is known to suppress the $\operatorname{rgd} 1 \Delta w s c 1 \Delta$ synthetic lethality, and co-deletion of RGD1 and MID2 leads to conditional lethality in the late-exponential growth phase (de Bettignies et al., 1999). Upon analysing the interaction between RGD1 and WSC1, we found that unregulated accumulation of Rho3 and Rho4 proteins was lethal in wsc $1 \Delta$ cells. However, accumulation of activated Rho3p and Rho4p had no effect in the mid $2 \Delta$ genetic background. Thus, Rho3 and Rho4 GTPases act differently on the partially redundant Wsc1 and Mid2 cell wall sensors. This is consistent with previous reports that, despite sharing a function in cell wall sensing, Wsclp and Mid2p have distinct roles in yeast (Sekiya-Kawasaki et al., 2002; Green et al., 2003). The interaction between MID2 and RGD1 must involve an Rgdlp function that is yet to be defined.

We also show that the PKC-MAP kinase pathway is not implicated in the $\operatorname{rgd} 1 \Delta w s c 1 \Delta$ synthetic lethality, and hence the lethality must involve a function of Wsclp that is different from its role as a cell wall stress sensor. Along the secretory route, distinct signalling pathways monitor 'traffic jams' and misfolding of proteins to slow down exocytosis and protein synthesis (Ng, 2001). In particular, it has been shown that the Wsc family of proteins is involved in interorganellar signal transduction in response to perturbations in exocytosis. The ASR utilizes Wsc proteins trapped along the secretory pathway to initiate relocation of proteins, and then transcriptional changes (Nanduri \& Tartakoff, 2001). The Bck1/Mkk1,2/Slt2 MAP kinase cascade activated by $\mathrm{Pkclp}$ is not required for the ASR, suggesting the existence of another branch of Pkclp signalling $(\mathrm{Ng}, 2001)$. We report that disturbances in Rho3p-mediated polarized exocytosis specifically decrease the abundance, and impair the processing, of Wsclp and Mid2p, although other proteins, such as the plasma membrane protein Fur4, were found to be unaltered. An important difference between these proteins is that Wsclp and Mid2p are highly glycosylated, whereas the Fur4 uracil permease is not (Silve et al., 1991; Lodder et al.,
1999; Philip \& Levin, 2001). It has been proposed that $O$ mannosylation increases the activity of Wsclp and Mid2p by enhancing their stability (Lommel et al., 2004). Moreover, the defects observed for Wscl and Mid2 proteins in the rho3 $\Delta$ mutant are similar to those reported in the protein $O$ mannosyltransferase pmt mutants (Lommel et al., 2004). Based on these results, it is likely that blocking the Rho3dependent polarized exocytosis impairs Wsclp and Mid2p glycosylation, thus affecting their stability and function. As a consequence, the Wscl protein can no longer function in signal transduction in rho3 mutants. These data support the idea that Wsclp, which is normally present on secretory vesicles, or in the plasma membrane, can no longer function when Rho3p-regulated polarized exocytosis is impaired. Together, our data show the existence of a specific functional relationship between Wsclp and Rho3/4 GTPases that could be linked to the regulation of polarized exocytosis.

Based on our results, the constitutive activation of the PKC pathway observed when both RGD1 and WSC1 are inactivated would be an indirect effect of perturbations in Rho3/ $4 \mathrm{p}$-regulated polarized exocytosis. In agreement with this analysis, we found that phosphorylated and total Slt $2 \mathrm{p}$ were increased in the rho3-V51 late-secretion mutant compared with WT cells (see Supplementary Fig. S1). Moreover, we observed that the PKC pathway was specifically activated upon production of GTP-bound Rho3p or Rho4p in WT cells. A strong cumulative effect was obtained when activated Rho3 and Rho4 GTPases were co-produced. No activation was observed when GDP-bound or WT forms of Rho3p and Rho4p were used (see Supplementary Fig. S1). Thus, either blocking or overactivating Rho3p-regulated secretion leads to an increase in the PKC pathway activity. Results obtained from rho3 $\Delta$ and rho $4 \Delta$ showed that Slt $2 p$ was not phosphorylated in these mutants, strongly suggesting that the activation is dependent on the presence of GTP-bound Rho3p and Rho4p in the cell. Interestingly, constitutive activation of the cell integrity pathway has also been reported for the $O$-mannosyltransferase $p m t 2 \Delta p m t 4 \Delta$ mutant, which is deficient in Wsclp and Mid2p posttranslational processing (Lommel et al., 2004). Taken together, these results demonstrate that the PKC pathway can be activated as a consequence of unbalanced polarized exocytosis, possibly through a decrease in active Wscl along the secretory pathway.

Overall, our analyses show that the genetic interaction observed between RGD1 and WSC1 may be the consequence of cumulative defects on polarized secretion. One hypothesis is that both Rgd1p and Wsclp are involved in the pathway down-regulating polarized exocytosis, which is dependent on Rho3 and Rho4 GTPases; the absence of one of the two proteins is partly compensated by the presence of the other under standard growth conditions. Nevertheless, when the mutant cells are subjected to additional stresses, such as unbalanced exocytosis, diauxic shift or high temperatures, down-regulation of polarized exocytosis is not sufficient, and the consequence is cell death. Future work 
will help to elucidate the precise mechanism involving both Rgdlp and Wsclp in the regulation of Rho3/4p-dependent polarized secretion.

\section{ACKNOWLEDGEMENTS}

We thank A. Claveres and M. F. Peypouquet for technical assistance. We are grateful to Dr P. Brennwald, University of North Carolina at Chapel Hill, USA, for providing the rho3-V51 and isogenic control strains, Dr D. Levin, Johns Hopkins Bloomberg School of Public Health, USA, for providing YEp352-Wsc1 ${ }^{3 \mathrm{HA}}$ and YEp352-Mid2 ${ }^{3 \mathrm{HA}}$ plasmids, and Dr A. Gangar for critical reading of the manuscript. The anti-GST-Slt2p antibodies were a kind gift from Drs H. Martin and M. Molina. The antibodies against Ure2p and Fur4p were provided by $\mathrm{Dr}$ C. Cullin, IBGC-Université Bordeaux 2, France, and Dr R. Haguenauer-Tsapis, Institut Jacques Monod, France, respectively. This work was supported by grants from the Université Victor Segalen Bordeaux 2 and the CNRS.

\section{REFERENCES}

Adamo, J. E., Rossi, G. \& Brennwald, P. (1999). The Rho GTPase Rho3 has a direct role in exocytosis that is distinct from its role in actin polarity. Mol Biol Cell 10, 4121-4133.

Adamo, J. E., Moskow, J. J., Gladfelter, A. S., Viterbo, D., Lew, D. J. \& Brennwald, P. J. (2001). Yeast Cdc42 functions at a late step in exocytosis, specifically during polarized growth of the emerging bud. J Cell Biol 155, 581-592.

Barthe, C., de Bettignies, G., Louvet, O., Peypouquet, M. F., Morel, C., Doignon, F. \& Crouzet, M. (1998). First characterization of the gene RGD1 in the yeast Saccharomyces cerevisiae. C R Acad Sci III 321, 453-462.

Cid, V. J., Duran, A., del Rey, F., Snyder, M. P., Nombela, C. \& Sanchez, M. (1995). Molecular basis of cell integrity and morphogenesis in Saccharomyces cerevisiae. Microbiol Rev 59, 345-386.

de Bettignies, G., Barthe, C., Morel, C., Peypouquet, M. F., Doignon, F. \& Crouzet, M. (1999). RGD1 genetically interacts with MID2 and SLG1, encoding two putative sensors for cell integrity signalling in Saccharomyces cerevisiae. Yeast 15, 1719-1731.

de Bettignies, G., Thoraval, D., Morel, C., Peypouquet, M. F. \& Crouzet, M. (2001). Overactivation of the protein kinase C-signaling pathway suppresses the defects of cells lacking the Rho3/Rho4-GAP Rgdlp in Saccharomyces cerevisiae. Genetics 159, 1435-1448.

Doignon, F., Weinachter, C., Roumanie, O. \& Crouzet, M. (1999). The yeast Rgdlp is a GTPase activating protein of the Rho3 and Rho4 proteins. FEBS Lett 459, 458-462.

Dong, Y., Pruyne, D. \& Bretscher, A. (2003). Formin-dependent actin assembly is regulated by distinct modes of Rho signaling in yeast. J Cell Biol 161, 1081-1092.

Etienne-Manneville, S. \& Hall, A. (2002). Rho GTPases in cell biology. Nature 420, 629-635.

Fernandez-Bellot, E., Guillemet, E., Ness, F., Baudin-Baillieu, A., Ripaud, L., Tuite, M. \& Cullin, C. (2002). The [URE3] phenotype: evidence for a soluble prion in yeast. EMBO Rep 3, 76-81.

Garcia-Ranea, J. A. \& Valencia, A. (1998). Distribution and functional diversification of the ras superfamily in Saccharomyces cerevisiae. FEBS Lett 434, 219-225.

Gari, E., Piedrafita, L., Aldea, M. \& Herrero, E. (1997). A set of vectors with a tetracycline-regulatable promoter system for modulated gene expression in Saccharomyces cerevisiae. Yeast 13, 837-848.
Gietz, R. D., Schiestl, R. H., Willems, A. R. \& Woods, R. A. (1995). Studies on the transformation of intact yeast cells by the LiAc/SSDNA/PEG procedure. Yeast 11, 355-360.

Gray, J. V., Ogas, J. P., Kamada, Y., Stone, M., Levin, D. E. \& Herskowitz, I. (1997). A role for the Pkcl MAP kinase pathway of Saccharomyces cerevisiae in bud emergence and identification of a putative upstream regulator. EMBO J 16, 4924-4937.

Green, R., Lesage, G., Sdicu, A. M., Menard, P. \& Bussey, H. (2003). A synthetic analysis of the Saccharomyces cerevisiae stress sensor Mid2p, and identification of a Mid2p-interacting protein, Zeolp, that modulates the PKC1-MPK1 cell integrity pathway. Microbiology 149, 2487-2499.

Gustin, M. C., Albertyn, J., Alexander, M. \& Davenport, K. (1998). MAP kinase pathways in the yeast Saccharomyces cerevisiae. Microbiol Mol Biol Rev 62, 1264-1300.

Heinisch, J. J., Lorberg, A., Schmitz, H. P. \& Jacoby, J. J. (1999). The protein kinase C-mediated MAP kinase pathway involved in the maintenance of cellular integrity in Saccharomyces cerevisiae. Mol Microbiol 32, 671-680.

Imai, J., Toh-e, A. \& Matsui, Y. (1996). Genetic analysis of the Saccharomyces cerevisiae $\mathrm{RHO} 3$ gene, encoding a rho-type small GTPase, provides evidence for a role in bud formation. Genetics 142, 359-369.

Jacoby, J. J., Nilius, S. M. \& Heinisch, J. J. (1998). A screen for upstream components of the yeast protein kinase C signal transduction pathway identifies the product of the SLG1 gene. Mol Gen Genet 258, 148-155.

Johnson, D. I. \& Pringle, J. R. (1990). Molecular characterization of CDC42, a Saccharomyces cerevisiae gene involved in the development of cell polarity. J Cell Biol 111, 143-152.

Kamada, Y., Jung, U. S., Piotrowski, J. \& Levin, D. E. (1995). The protein kinase C-activated MAP kinase pathway of Saccharomyces cerevisiae mediates a novel aspect of the heat shock response. Genes Dev 9, 1559-1571.

Kamada, Y., Qadota, H., Python, C. P., Anraku, Y., Ohya, Y. \& Levin, D. E. (1996). Activation of yeast protein kinase C by Rhol GTPase. J Biol Chem 271, 9193-9196.

Ketela, T., Green, R. \& Bussey, H. (1999). Saccharomyces cerevisiae mid2p is a potential cell wall stress sensor and upstream activator of the PKC1-MPK1 cell integrity pathway. J Bacteriol 181, 3330-3340.

Kosodo, Y., Imai, K., Hirata, A., Noda, Y., Takatsuki, A., Adachi, H. \& Yoda, K. (2001). Multicopy suppressors of the sly1 temperaturesensitive mutation in the ER-Golgi vesicular transport in Saccharomyces cerevisiae. Yeast 18, 1003-1014.

Lee, K. S., Irie, K., Gotoh, Y., Watanabe, Y., Araki, H., Nishida, E., Matsumoto, K. \& Levin, D. E. (1993). A yeast mitogen-activated protein kinase homolog (Mpklp) mediates signalling by protein kinase C. Mol Cell Biol 13, 3067-3075.

Lodder, A. L., Lee, T. K. \& Ballester, R. (1999). Characterization of the Wscl protein, a putative receptor in the stress response of Saccharomyces cerevisiae. Genetics 152, 1487-1499.

Lommel, M., Bagnat, M. \& Strahl, S. (2004). Aberrant processing of the WSC family and Mid2p cell surface sensors results in cell death of Saccharomyces cerevisiae O-mannosylation mutants. Mol Cell Biol 24, 46-57.

Martin, H., Rodriguez-Pachon, J. M., Ruiz, C., Nombela, C. \& Molina, M. (2000). Regulatory mechanisms for modulation of signaling through the cell integrity Slt2-mediated pathway in Saccharomyces cerevisiae. J Biol Chem 275, 1511-1519.

Matsui, Y. \& Toh-e, A. (1992a). Isolation and characterization of two novel ras superfamily genes in Saccharomyces cerevisiae. Gene 114, 43-49. 
Matsui, Y. \& Toh-e, A. (1992b). Yeast RHO3 and RHO4 ras superfamily genes are necessary for bud growth, and their defect is suppressed by a high dose of bud formation genes CDC42 and BEM1. Mol Cell Biol 12, 5690-5699.

Nanduri, J. \& Tartakoff, A. M. (2001). The arrest of secretion response in yeast: signaling from the secretory path to the nucleus via Wsc proteins and Pkclp. Mol Cell 8, 281-289.

$\mathrm{Ng}$, D. T. (2001). Interorganellar signal transduction: the arrest of secretion response. Dev Cell 1, 319-320.

Nonaka, H., Tanaka, K., Hirano, H., Fujiwara, T., Kohno, H., Umikawa, M., Mino, A. \& Takai, Y. (1995). A downstream target of $\mathrm{RHO1}$ small GTP-binding protein is $\mathrm{PKC1}$, a homolog of protein kinase $\mathrm{C}$, which leads to activation of the MAP kinase cascade in Saccharomyces cerevisiae. EMBO J 14, 5931-5938.

Philip, B. \& Levin, D. E. (2001). Wsc1 and Mid2 are cell surface sensors for cell wall integrity signaling that act through Rom2, a guanine nucleotide exchange factor for Rho1. Mol Cell Biol 21, 271-280.

Rajavel, M., Philip, B., Buehrer, B. M., Errede, B. \& Levin, D. E. (1999). Mid2 is a putative sensor for cell integrity signaling in Saccharomyces cerevisiae. Mol Cell Biol 19, 3969-3976.

Riezman, H., Hase, T., van Loon, A. P., Grivell, L. A., Suda, K. \& Schatz, G. (1983). Import of proteins into mitochondria: a 70 kilodalton outer membrane protein with a large carboxy-terminal deletion is still transported to the outer membrane. EMBO J 2, 2161-2168.

Robinson, N. G., Guo, L., Imai, J., Toh-e. A., Matsui, Y. \& Tamanoi, F. (1999). Rho3 of Saccharomyces cerevisiae, which regulates the actin cytoskeleton and exocytosis, is a GTPase which interacts with Myo2 and Exo70. Mol Cell Biol 19, 3580-3587.

Rose, A. H. (1975). Growth and handling of yeasts. Methods Cell Biol 12, 1-16.

Roumanie, O., Peypouquet, M. F., Bonneu, M., Thoraval, D., Doignon, F. \& Crouzet, M. (2000). Evidence for the genetic interaction between the actin-binding protein Vrpl and the RhoGAP Rgd1 mediated through Rho3p and Rho4p in Saccharomyces cerevisiae. Mol Microbiol 36, 1403-1414.
Roumanie, O., Weinachter, C., Larrieu, I., Crouzet, M. \& Doignon, F. (2001). Functional characterization of the Bag7, Lrg1 and Rgd2 RhoGAP proteins from Saccharomyces cerevisiae. FEBS Lett 506, 149-156.

Roumanie, O., Peypouquet, M. F., Thoraval, D., Doignon, F. \& Crouzet, M. (2002). Functional interactions between the VRP1LAS17 and RHO3-RHO4 genes involved in actin cytoskeleton organization in Saccharomyces cerevisiae. Curr Genet 40, 317-325.

Roumanie, O., Wu, H., Molk, J. N., Rossi, G., Bloom, K. \& Brennwald, P. (2005). Rho GTPase regulation of exocytosis in yeast is independent of GTP hydrolysis and polarization of the exocyst complex. J Cell Biol 170, 583-594.

Schmitz, H. P., Huppert, S., Lorberg, A. \& Heinisch, J. J. (2002). Rho5p downregulates the yeast cell integrity pathway. J Cell Sci 115, 3139-3148.

Sekiya-Kawasaki, M., Abe, M., Saka, A., Watanabe, D., Kono, K., Minemura-Asakawa, M., Ishihara, S., Watanabe, T. \& Ohya, Y. (2002). Dissection of upstream regulatory components of the Rholp effector, 1,3- $\beta$-glucan synthase, in Saccharomyces cerevisiae. Genetics 162, 663-676.

Sherman, F., Fink, G. R. \& Hicks, J. B. (1986). Methods in Yeast Genetics: a Laboratory Course Manual. Cold Spring Harbor, NY: Cold Spring Harbor Laboratory.

Silve, S., Volland, C., Garnier, C., Jund, R., Chevallier, M. R. \& Haguenauer-Tsapis, R. (1991). Membrane insertion of uracil permease, a polytopic yeast plasma membrane protein. Mol Cell Biol 11, 1114-1124.

Van Aelst, L. \& D'Souza-Schorey, C. (1997). Rho GTPases and signaling networks. Genes Dev 11, 2295-2322.

Verna, J., Lodder, A., Lee, K., Vagts, A. \& Ballester, R. (1997). A family of genes required for maintenance of cell wall integrity and for the stress response in Saccharomyces cerevisiae. Proc Natl Acad Sci U S A 94, 13804-13809.

Winston, F., Dollard, C. \& Ricupero-Hovasse, S. L. (1995) Construction of a set of convenient Saccharomyces cerevisiae strains that are isogenic to S288C. Yeast 11, 53-55. 